\title{
Application of Passivity-Based Control and Time-Frequency Representation in a Doubly Fed Induction Generator System
}

\author{
Yingpei Liu and Haiping Liang \\ School of Electrical and Electronic Engineering, North China Electric Power University, Baoding 071003, China \\ Correspondence should be addressed to Yingpei Liu; liuyingpei_123@126.com
}

Received 25 March 2015; Revised 26 June 2015; Accepted 30 July 2015

Academic Editor: Reik Donner

Copyright ( 2015 Y. Liu and H. Liang. This is an open access article distributed under the Creative Commons Attribution License, which permits unrestricted use, distribution, and reproduction in any medium, provided the original work is properly cited.

\begin{abstract}
In order to improve the performance of a doubly fed induction generator (DFIG) system, we put forward a high performance nonlinear passivity-based control (PBC) method on DFIG. Firstly, we build a PBC mathematical model for DFIG. We design the passive controller for the inner loop in the control system based on passivity theory. Then we calculate the rotor's control voltages which are modulated afterwards to pulse to control the rotor side converter. The maximal wind energy capture is effectively realized. The rotor speed and DFIG currents fast track their expected values. The independent regulation of the stator active power and reactive power is achieved. Finally we perform simulations to verify the effectiveness of the proposed method. Furthermore, we employ the Wigner-Ville distribution (WVD) and continuous wavelet transform (CWT) as two time-frequency representation methods to indicate that the proposed method in the paper performs well from the perspective of energy distribution in time and frequency domain.
\end{abstract}

\section{Introduction}

Recently, owing to the depletion of fossil fuels such as oil, natural gas, and coal, and the serious environmental pollution caused by fossil fuels burning, the development and utilization of wind energy which is renewable and completely green is of great significance throughout the world. The doubly fed induction generator (DFIG), which can operate on variable-speed constant-frequency (VSCF) mode, has been widely studied revealing its excellent performance $[1,2]$. Usually, a vector control strategy based on stator flux linkage orientation is applied to the DFIG wind power generation system [3]. The essence of a vector control strategy is the progressive feedback linearization, which comes at the expense of the system's nonlinear precise offset. Thus, the vector control is essentially nonrobust. In view of the fact that DFIG is a typical nonlinear, multivariable, and strong coupling system $[4,5]$, the traditional vector control strategy applied to DFIG has some disadvantages, such as depending on the system's parameters, and tending to have current distortion when the load changes. Therefore, the traditional vector control scheme based on the system's linearized model does not have excellent control performances when wind speed changes rapidly or when motor parameters such as its resistance change during motor operation.

Compared to the traditional vector control method, the passivity-based control (PBC) theory has shown superior control performance. From the point of view of energy, PBC theory seeks the energy function related to the controlled variable. Based on the designed passive controller, the energy function tracks the expected energy function so as to achieve the control objective. In detail, the reactive component in the energy dissipation of the system is configured in order to force the system's total energy to track the expected energy function. Therefore, the stability of the system is ensured, and the system's state variables asymptotically converge to their set values, and also the outputs of the controlled object asymptotically converge to their desired values. Compared to the linearization control method, the superiority of the PBC method lies in the designed passive controller which focuses on the natural properties of the object. Accordingly, the system's robustness is effectively improved, and the control law designed for PBC controller ensures that the system is globally stable with no divergent singular point. 


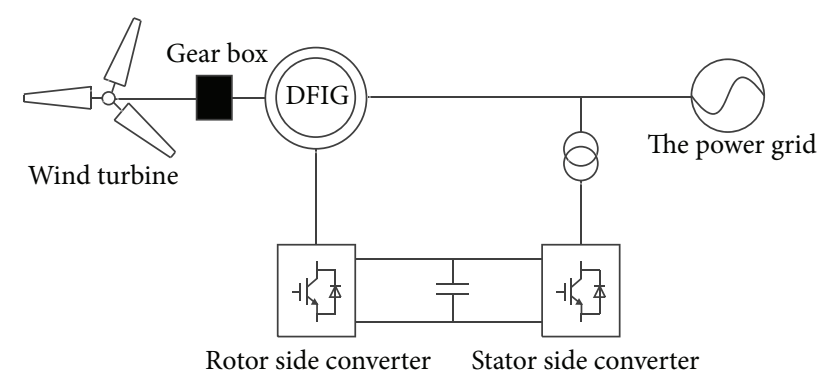

FIGURE 1: Schematic diagram of the DFIG wind power generation system.

Based on the above advantages of $\mathrm{PBC}$ theory, passivity control of an asynchronous motor has been studied and some significant progress has been made [6-9]. Reference [10] presents a passivity controller for DFIG in a twophase stationary reference frame, but the expression of the derivation control law is too complex. In addition, it does not concern the regulation of the stator's reactive power and active power.

In order to solve the above problems, in this paper we propose a nonlinear $\mathrm{PBC}$ method with high performance for the DFIG system. We build the PBC model of a DFIG and prove its passivity. Then we design the passive controller for the inner loop based on passivity theory. Furthermore, we perform simulation experiments to verify the effectiveness of the proposed method.

On the other hand, DFIG system signals are time series signals. Time series analysis has attracted a great deal of attention from different research fields. Time-frequency representation can simultaneously present the energy characteristics in time and frequency plane. In this paper we implement the Wigner-Ville distribution (WVD) and continuous wavelet transform (CWT) as two time-frequency representation methods to analyze the DFIG system's signals. The results indicate that our proposed method performs well from the perspective of energy distribution in time and frequency domain.

The organization of this paper is as follows. Section 2 describes the maximal wind energy capture theory, the $\mathrm{PBC}$ model of DFIG, and the passive controller design for the DFIG system. In Section 3, we perform simulations and use time-frequency representation methods to analyze the system's signals to verify the effectiveness of the proposed method. The conclusions are presented in Section 4.

\section{Materials and Methods}

2.1. Maximal Wind Energy Capture Theory. The VSCF DFIG wind power generation system is shown in Figure 1. It includes wind turbine, gear box, DFIG, rotor side converter, grid side converter, and the power grid [11]. Firstly, the wind turbine converts wind energy to mechanical power. Then, the gear box connected to the wind turbine drives the DFIG rotor to rotate; thereby the mechanical power is passed to the DFIG [12]. The stator side converter and rotor side converter are used to supply the exciter field current to the rotor winding of DFIG. The working process is as follows. When the rotor speed is slower than the synchronous speed, the converter at the stator side operates on rectifier mode and the rotor side converter on inverter mode. Conversely, when the rotor speed is higher than synchronous speed, the stator side converter operates on inverter mode and the rotor side converter on rectifier mode. Therefore, the exciter field current flows through the rotor winding to establish a magnetic field, and due to the rotor rotation, an induction current in the stator winding is produced which achieves the electric energy conversion from wind energy [13].

According to the aerodynamics principle, for a given wind speed $v$ and area $S$, the wind power is computed as

$$
P_{w}=\frac{1}{2} \rho v^{3} S
$$

where $\rho$ is the air density.

We define the wind energy utilization coefficient $C_{p}(\lambda, \beta)$, which represents the wind energy's conversion efficiency for the wind turbine. It is a function of the tip speed ratio $\lambda$ and the blade pitch angle $\beta$. Then, we can represent the actual mechanical power output $P_{m}$ by the wind turbine as follows [14-16]:

$$
P_{m}=\frac{1}{2} \rho v^{3} S C_{p}(\lambda, \beta)
$$

The tip speed ratio $\lambda$, which is the ratio of blade tip speed and wind speed, is defined as

$$
\lambda=\frac{\omega R}{v},
$$

where $R$ is the blade radius and $\omega$ is the wind turbine speed.

When the blade pitch angle $\beta$ is constant, $C_{p}$ can reach its maximum value $C_{p \max }$ only when $\lambda$ takes a certain value $\lambda_{\text {opt }}$. At this moment, the mechanical power output by the wind turbine can reach its maximum value $P_{m \_ \text {max }}$, which is the value of the maximal wind energy capture. $P_{m \_ \text {max }}$ is expressed as follows:

$$
P_{m \_ \text {max }}=\frac{1}{2} \rho S\left(\frac{R}{\lambda_{\mathrm{opt}}}\right)^{3} \omega_{\mathrm{opt}}^{3} C_{p \max }\left(\lambda_{\mathrm{opt}}, \beta\right),
$$

where $\omega_{\text {opt }}$ is the rotation speed of the wind turbine under the maximal wind energy capture.

Corresponding to $\omega_{\text {opt }}$, there exists an optimal rotor speed $\omega_{r}$ for the DFIG. The maximal wind energy capture can be achieved through a closed-loop control of the DFIG's rotor speed $\omega_{r}$.

2.2. The PBC Model of DFIG. Figure 2 shows the two-phase rotating reference frame $(d-q)$, in which the $(a, b, c)$ coordinate axes denote the three-phase stationary reference frame, and the $(d, q)$ axes denote the two-phase rotating reference frame with the rotating speed $\omega_{r}$. The mathematical model of DFIG in the rotating reference frame is represented in the following, including voltage equation, flux-linkage equation, electromagnetic torque equation, and motion equation [1719]. 


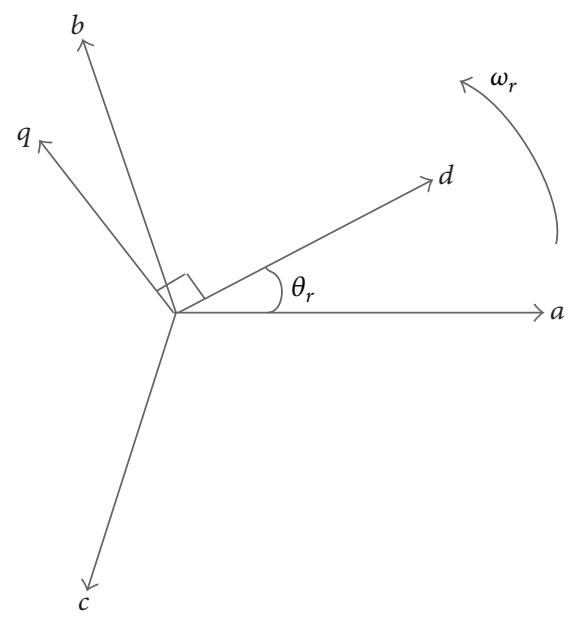

FIGURE 2: Schematic diagram of the two-phase rotating reference frame.

The voltage equation is

$$
\begin{aligned}
& u_{s d}=R_{s} i_{s d}+p \psi_{s d}-\omega_{s} \psi_{s q}, \\
& u_{s q}=R_{s} i_{s q}+p \psi_{s q}+\omega_{s} \psi_{s d},
\end{aligned}
$$

$$
\left[\begin{array}{l}
u_{s d} \\
u_{s q} \\
u_{r d} \\
u_{r q}
\end{array}\right]=\left[\begin{array}{cccc}
R_{s}+p L_{s} & -\omega_{s} L_{s} & p L_{m} & -\omega_{s} L_{m} \\
\omega_{s} L_{s} & R_{s}+p L_{s} & \omega_{s} L_{m} & p L_{m} \\
p L_{m} & -\left(\omega_{s}-\omega_{r}\right) L_{m} & R_{r}+p L_{r} & -\left(\omega_{s}-\omega_{r}\right) L_{m} \\
\left(\omega_{s}-\omega_{r}\right) L_{m} & p L_{m} & \left(\omega_{s}-\omega_{r}\right) L_{r} & R_{r}+p L_{r}
\end{array}\right]\left[\begin{array}{c}
i_{s d} \\
i_{s q} \\
i_{r d} \\
i_{r q}
\end{array}\right] .
$$

The electromagnetic torque equation is

$$
\begin{aligned}
T_{e} & =1.5 n_{p}\left(i_{s q} \psi_{s d}-i_{s d} \psi_{s q}\right) \\
& =1.5 n_{p} L_{m}\left(i_{s q} i_{r d}-i_{s d} i_{r q}\right),
\end{aligned}
$$

where $T_{e}$ is the electromagnetic torque and $n_{p}$ is the number of pole pairs.

The motion equation of the DFIG is

$$
\frac{J}{n_{p}} \frac{d \omega_{r}}{d t}+\frac{B}{n_{p}} \omega_{r}=T_{m}-T_{e}
$$

where $J$ is the rotary inertia of DFIG, $B$ is friction coefficient, and $T_{m}$ is the wind turbine's mechanical torque.

Based on PBC theory, from (7), we can express the PBC model of DFIG as

$$
M \dot{x}+b x+R x+W=F u
$$

$$
\begin{aligned}
& u_{r d}=R_{r} i_{r d}+p \psi_{r d}-\left(\omega_{s}-\omega_{r}\right) \psi_{r q}, \\
& u_{r q}=R_{r} i_{r q}+p \psi_{r q}+\left(\omega_{s}-\omega_{r}\right) \psi_{r d},
\end{aligned}
$$

where the subscript $d$ denotes the $d$-axis component; the subscript $q$ denotes the $q$-axis component; $u_{s d}, u_{s q}$ are stator voltages; $u_{r d}, u_{r q}$ are rotor voltages; $i_{s d}, i_{s q}$ are stator currents; $i_{r d}, i_{r q}$ are rotor currents; $\psi_{s d}, \psi_{s q}$ are stator flux linkages; $\psi_{r d}$, $\psi_{r q}$ are rotor flux linkages; $R_{s}$ is the stator resistance; $R_{r}$ is the rotor resistance; $\omega_{s}$ is the stator synchronous speed; $\omega_{r}$ is the rotor speed of DFIG; and $p=d / d t$ is the differential operator.

The flux-linkage equation is

$$
\begin{aligned}
& \psi_{s d}=L_{s} i_{s d}+L_{m} i_{r d}, \\
& \psi_{s q}=L_{s} i_{s q}+L_{m} i_{r q}, \\
& \psi_{r d}=L_{r} i_{r d}+L_{m} i_{s d}, \\
& \psi_{r q}=L_{r} i_{r q}+L_{m} i_{s q},
\end{aligned}
$$

where $L_{s}$ is the self-inductance of the stator, $L_{r}$ is the selfinductance of the rotor, and $L_{m}$ is the mutual inductance.

Substituting (6) into (5) yields

where

$$
\begin{aligned}
& x=\left[\begin{array}{llll}
i_{s d} & i_{s q} & i_{r d} & i_{r q}
\end{array}\right]^{T} ; \\
& M=\left[\begin{array}{cc}
L_{s} I & L_{m} I \\
L_{m} I & L_{r} I
\end{array}\right] \text {; } \\
& b=\left[\begin{array}{cc}
L_{s} K & L_{m} K \\
L_{m} K & L_{r} K
\end{array}\right]\left(\omega_{s}-\omega_{r}\right) \text {; } \\
& K=\left[\begin{array}{cc}
0 & -1 \\
1 & 0
\end{array}\right] \text {; } \\
& R=\left[\begin{array}{cc}
R_{s} I & 0 \\
0 & R_{r} I
\end{array}\right] \\
& F=\left[\begin{array}{ll}
I & 0 \\
0 & I
\end{array}\right] \text {; } \\
& u=\left[\begin{array}{llll}
u_{s d} & u_{s q} & u_{r d} & u_{r q}
\end{array}\right]^{T} ;
\end{aligned}
$$

W

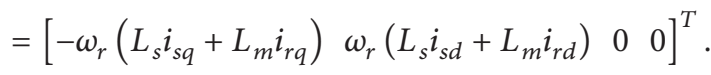


From the above, we can see that $M$ is a symmetric matrix; $R$ is a symmetric positive definite matrix; and $b$ is an antisymmetric matrix; that is to say, $b=-b^{T}$, which consists of $L_{s}, L_{r}$, and the mutual inductance $L_{m}$ indicating the interconnected structure of stator and rotor in the DFIG system.

2.3. Passive Controller Design for DFIG System. When the system works, there exists a winding capacitance effect between the stator winding and rotor winding. Because its value is small, we ignore this winding capacitance effect in the following. The energy function $V_{1}$ of the electric component in the DFIG can be defined as

$$
V_{1}=\frac{1}{2} x^{T} M x
$$

By derivation of (12) and substituting (10), we obtain

$$
\dot{V}_{1}=x^{T} M \dot{x}=-x^{T} b x+x^{T}(-R x+F u-W) .
$$

Since the matrix $b$ is an antisymmetric matrix, $x^{T} b x=0$, and hence $\dot{V}_{1}=x^{T}(-R x+F u-W)$.

Through integration of (13), we obtain

$$
\begin{aligned}
V_{1}(t)-V_{1}\left(t_{0}\right)= & \int_{t_{0}}^{t}\left(x^{T} F u\right) d t-\int_{t_{0}}^{t}\left(x^{T} W\right) d t \\
& -\int_{t_{0}}^{t}\left(x^{T} R x\right) d t
\end{aligned}
$$

which implies

$$
V_{1}(t)-V_{1}\left(t_{0}\right)<\int_{t_{0}}^{t}\left(x^{T} F u\right) d t
$$

In order to achieve a stator flux linkage orientation, the control objectives for the DFIG system are as follows:

(a) Electromagnet torque asymptotic track: $\lim _{t \rightarrow \infty}\left(T_{e}-\right.$ $\left.T_{e}^{*}\right)=0$.

(b) Stator flux linkage orientation and asymptotic track:

$$
\begin{aligned}
& \lim _{t \rightarrow \infty} \psi_{s q}=\lim _{t \rightarrow \infty}\left(L_{s} i_{s q}+L_{m} i_{r q}\right)=0 ; \\
& \lim _{t \rightarrow \infty} \psi_{s d}=\lim _{t \rightarrow \infty}\left(L_{s} i_{s d}+L_{m} i_{r d}\right)=\psi_{s}^{*},
\end{aligned}
$$

where $T_{e}^{*}$ is the expected value of the electromagnetic torque and $\psi_{s}^{*}$ is the expected value of stator flux linkage.

In the two-phase rotating reference frame, the expected electromagnetic torque is calculated as follows:

$$
T_{e}^{*}=\frac{3}{2} n_{p} L_{m}\left(i_{s q}^{*} i_{r d}^{*}-i_{s d}^{*} i_{r q}^{*}\right)
$$

From the control objectives, we have

$$
\begin{aligned}
& L_{s} i_{s d}^{*}+L_{m} i_{r d}^{*}=\psi_{s}^{*}, \\
& L_{s} i_{s q}^{*}+L_{m} i_{r q}^{*}=0,
\end{aligned}
$$

where $i_{s d}^{*}, i_{s q}^{*}$ denote the expected stator current and $i_{r d}^{*}, i_{r q}^{*}$ the expected rotor current.

In the control system based on stator flux linkage orientation, the stator's active power and reactive power are in direct proportion to the active component and reactive component of the stator current, respectively.

We describe the expected stator's reactive power $Q_{s}^{*}$ as

$$
Q_{s}^{*}=\frac{3}{2} U_{m} i_{s d}^{*}
$$

where $U_{m}$ is the amplitude of stator voltage vector.

Thus, the $d$-q-axis components of expected stator current and rotor current $i_{s d}^{*}, i_{s q}^{*}, i_{r d}^{*}$, and $i_{r q}^{*}$ are derived from (17), (18), and (19) as

$$
\begin{aligned}
& i_{s d}^{*}=\frac{2 Q_{s}^{*}}{3 U_{m}}, \\
& i_{s q}^{*}=\frac{2 T_{e}^{*}}{3 n_{p} \psi_{s}^{*}}, \\
& i_{r d}^{*}=\frac{3 \psi_{s}^{*} U_{m}-2 L_{s} Q_{s}^{*}}{3 U_{m} L_{m}}, \\
& i_{r q}^{*}=-\frac{2 T_{e}^{*} L_{s}}{3 n_{p} \psi_{s}^{*} L_{m}} .
\end{aligned}
$$

We define the expected state variables $x^{*}=$ $\left[\begin{array}{llll}i_{s d}^{*} & i_{s q}^{*} & i_{r d}^{*} & i_{r q}^{*}\end{array}\right]^{T}$ and then consider the state variables error $e=x-x^{*}$. According to the above, the equation of state error is

$$
M \dot{e}+(b+R) e=\xi
$$

where $\xi$ is the disturbance and $\xi=F u-\left[M \dot{x}^{*}+(b+R) x^{*}+W\right]$.

In accordance with (21), the energy function $V_{2}$ is given by

$$
V_{2}=\frac{1}{2} e^{T} M e
$$

We calculate the eigenvalues of the matrix $M$. The results are as follows:

$$
\begin{aligned}
& \delta_{1}=\left[L_{s}+L_{r}+\frac{\sqrt{\left(L_{s}-L_{r}\right)^{2}+4 L_{m}^{2}}}{2}\right], \\
& \delta_{2}=\left[L_{s}+L_{r}-\frac{\sqrt{\left(L_{s}-L_{r}\right)^{2}+4 L_{m}^{2}}}{2}\right] .
\end{aligned}
$$

We know that $L_{s}>L_{m}, L_{r}>L_{m}$, so $L_{s} L_{r}>L_{m}^{2}$. Then we obtain $\left(L_{s}+L_{r}\right)^{2}-\left[\left(L_{s}-L_{r}\right)^{2}+4 L_{m}^{2}\right]=4\left(L_{s} L_{r}-L_{m}^{2}\right)>0$. Consequently, $L_{s}+L_{r}>\sqrt{\left(L_{s}-L_{r}\right)^{2}+4 L_{m}^{2}}$; that is to say, $\delta_{1}>0$ and $\delta_{2}>0$. Therefore, we draw the conclusion that the symmetric matrix $M$ is positive definite, and $V_{2}>0$. 


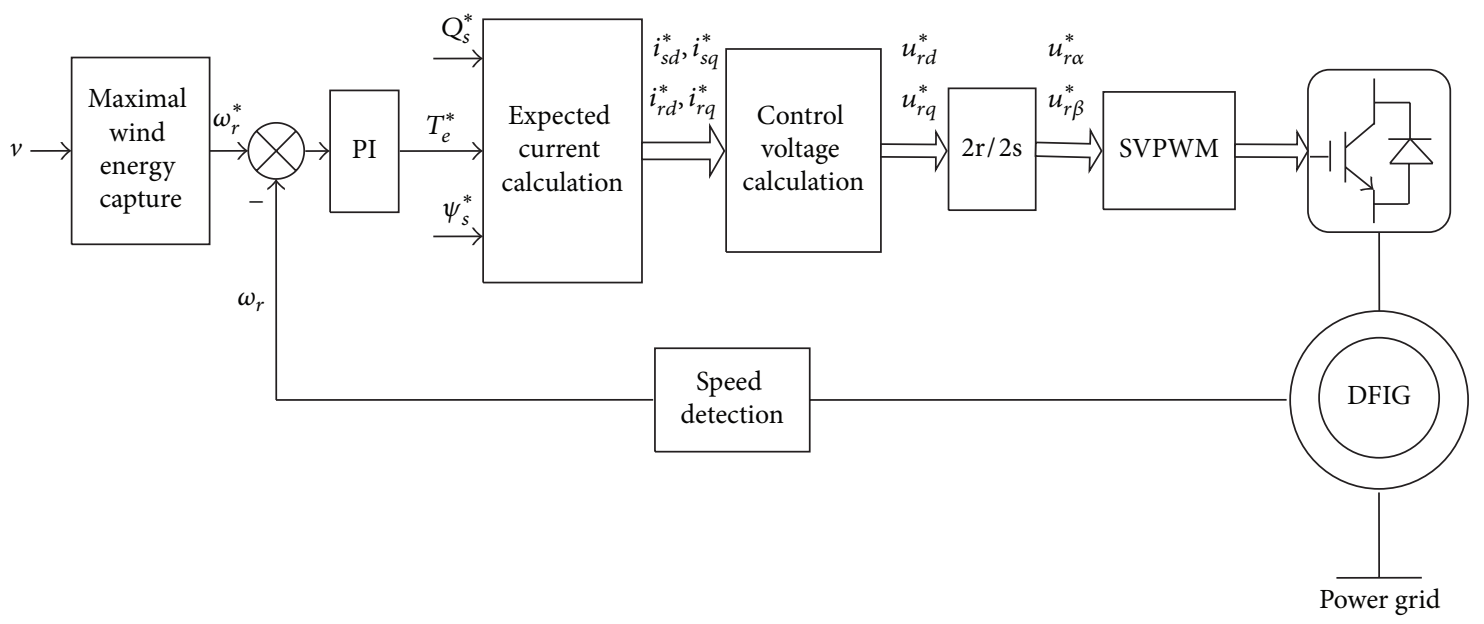

FIGURE 3: Schematic diagram of the passivity-based control for the DFIG system.

By derivation of (22), we get

$$
\dot{V}_{2}=e^{T} M \dot{e}=e^{T} \xi-e^{T}(b+R) e .
$$

$b$ is an antisymmetric matrix; thus $e^{T} b e=0$. Then we obtain

$$
\dot{V}_{2}=e^{T} \xi-e^{T} R e .
$$

According to Lyapunov stability theory, if $\xi \equiv 0$, then $\dot{V}_{2}<0$. Besides, $V_{2}>0$, for this reason, the state variables error $e$ asymptotically converges to zero; in other words, the state variables $x$ asymptotically converge to the expected state variables $x^{*}$.

Then, from the condition $\xi=0$, we easily get

$$
F u=M \dot{x}^{*}+(b+R) x^{*}+W .
$$

Substitute $F, M, b, R, W$, and $x^{*}$ into (26); the $d$-q-axis components of expected rotor voltage $u_{r d}^{*}, u_{r q}^{*}$ are obtained:

$$
\begin{aligned}
u_{r d}^{*}= & L_{m} p i_{s d}^{*}+L_{r} p i_{r d}^{*}-\left(\omega_{s}-\omega_{r}\right) L_{m} i_{s q}^{*}-\omega_{s} L_{r} i_{r q}^{*} \\
& +R_{r} i_{r d}^{*} \\
u_{r q}^{*}= & L_{m} p i_{s q}^{*}+L_{r} p i_{r q}^{*}-\left(\omega_{s}-\omega_{r}\right) L_{m} i_{s q}^{*}+\omega_{s} L_{r} i_{r d}^{*} \\
& +R_{r} i_{r q}^{*} .
\end{aligned}
$$

In order to reach a satisfactory dynamic performance, that is to say, to have fast convergence to the expected value, we add a damper to (27):

$$
\begin{aligned}
u_{r d}^{*}= & L_{m} p i_{s d}^{*}+L_{r} p i_{r d}^{*}-\omega_{s} L_{m} i_{s q}^{*}-\left(\omega_{s}-\omega_{r}\right) L_{r} i_{r q}^{*} \\
& +R_{r} i_{r d}^{*}-k_{1}\left(i_{r d}-i_{r d}^{*}\right), \\
u_{r q}^{*}= & L_{m} p i_{s q}^{*}+L_{r} p i_{r q}^{*}-\omega_{s} L_{m} i_{s q}^{*}+\left(\omega_{s}-\omega_{r}\right) L_{r} i_{r d}^{*} \\
& +R_{r} i_{r q}^{*}-k_{2}\left(i_{r q}-i_{r q}^{*}\right)
\end{aligned}
$$

where $k_{1}$ and $k_{2}$ are damping coefficients.
According to the theory above, we construct the schematic diagram of a passivity-based control for the DFIG system shown in Figure 3. The working process is carried out as follows. With the input signal of wind speed $v$, we obtain the expected rotor speed $\omega_{r}^{*}$ based on the maximal wind energy capture theory. The expected electromagnetic torque $T_{e}^{*}$ is calculated by the PI controller with the input signals of $\omega_{r}$ and $\omega_{r}^{*}$. Using $Q_{s}^{*}, \psi_{s}^{*}$, the expected currents are obtained. Then, according to (28) and transformation from two-phase rotating reference frame to two-phase stationary reference frame $(2 r / 2 s)$, we get $u_{r \alpha}^{*}, u_{r \beta}^{*}$, which are afterwards modulated by space vector pulse width modulation (SVPWM).

\section{Results and Discussion}

In order to verify the effectiveness of our proposed strategy, according to the theory above, we construct a simulation model of the wind power generation system using MATLAB/SIMULINK. The simulation condition is as follows. The initial wind speed is $3 \mathrm{~m} / \mathrm{s}$. At $t=5 \mathrm{~s}$, the wind speed increases to $5 \mathrm{~m} / \mathrm{s}$. The expected stator reactive power $Q_{s}^{*}$ is kept constant at zero. The simulation results for our proposed method are shown in Figure 4.

Figure 4(a) presents the actual rotor speed and the expected rotor speed waves of the DFIG. In regard to the steady-state performance, we can see that when the wind speed increases from $3 \mathrm{~m} / \mathrm{s}$ to $5 \mathrm{~m} / \mathrm{s}$ at $t=5 \mathrm{~s}$, the expected rotor speed of DFIG $\omega_{r}^{*}$ suddenly increases from $66 \mathrm{rad} / \mathrm{s}$ to $82 \mathrm{rad} / \mathrm{s}$ at $t=5 \mathrm{~s}$, which indicates that the DFIG system operates well according to the maximal wind energy capture theory. In addition to this, we can see that, for our proposed passivity-based control method, the actual rotor speed of DFIG $\omega_{r}$ quickly tracks its expected value $\omega_{r}^{*}$.

Figure 4(b) shows the rotor current wave. We can see that the amplitude of $i_{r}$ keeps constant when the wind speed increases at $t=5 \mathrm{~s}$. Besides, it can be easily found that, after $t=5 \mathrm{~s}$, the frequency of $i_{r}$ decreases. The reason is that, according to the maximal wind energy capture theory, the rotor speed increases after $t=5 \mathrm{~s}$ 


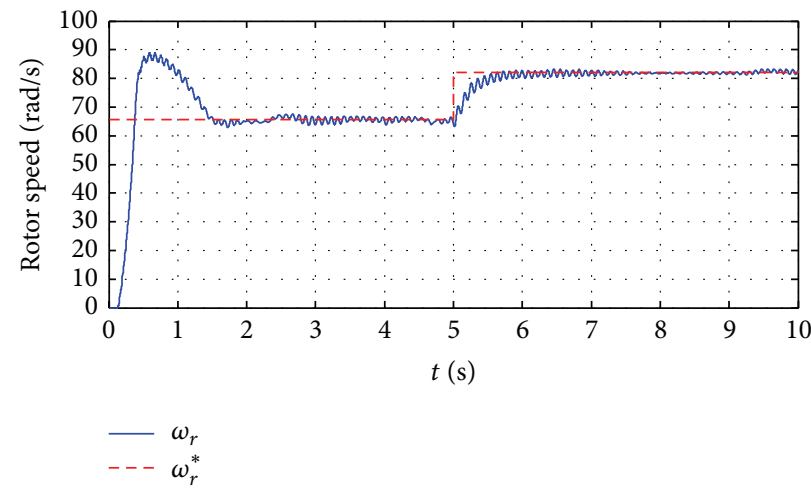

(a)

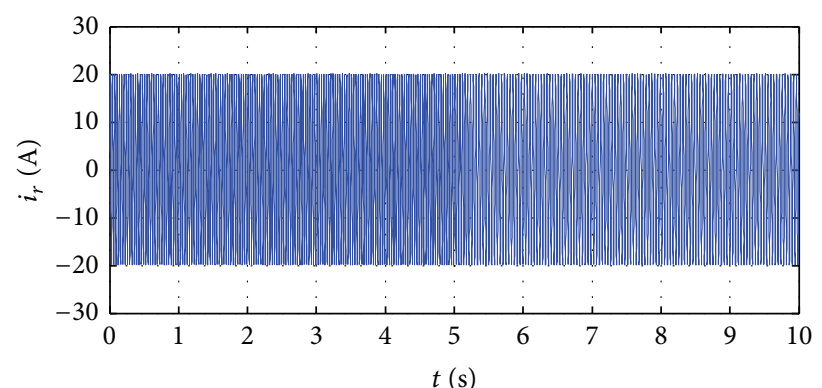

(b)

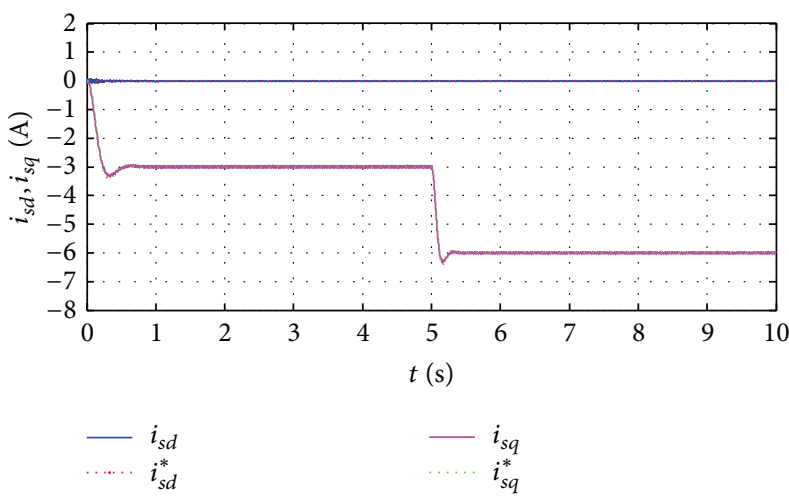

(d)

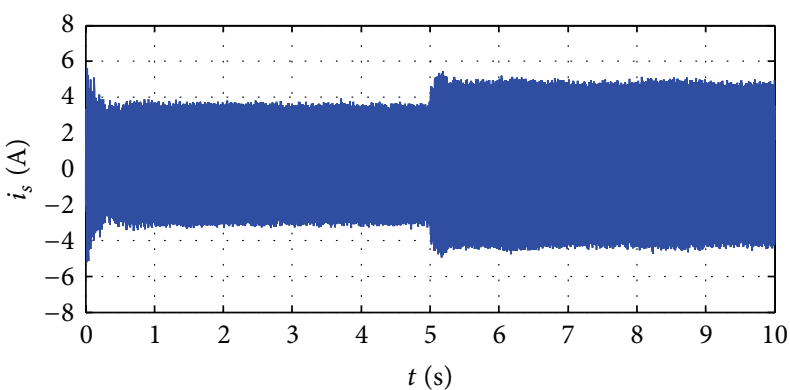

(c)

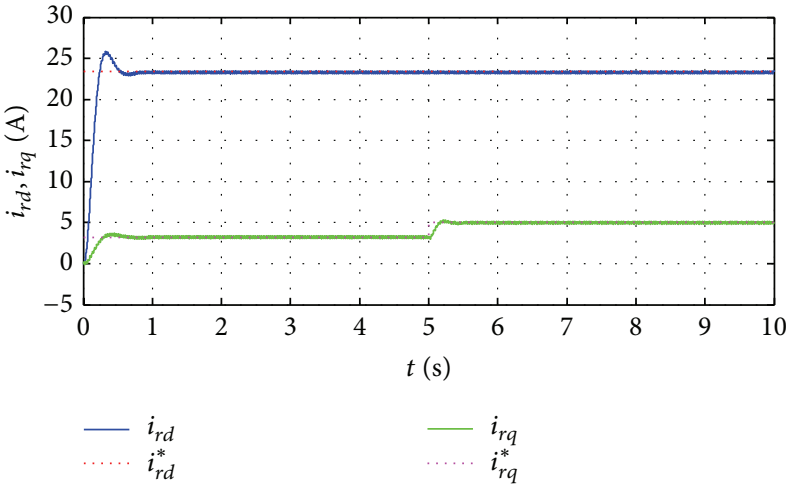

(e)

FiguRE 4: Simulation results: (a) actual rotor speed and expected rotor speed waves of the DFIG, (b) rotor current wave, (c) stator current wave, (d) $d$-q-axis components of expected and the actual stator current waves, and (e) $d$-q-axis components of expected and the actual rotor current waves.

when wind speed becomes stronger. Through our proposed control strategy, the frequency of $i_{r}$ should be reduced in order to keep the frequency of three-phase stator currents constant.

Figure 4(c) presents the stator current wave. It can be seen that the $i_{s}$ amplitude increases rapidly when the wind speed gets stronger after $t=5 \mathrm{~s}$. Also, we can see that the frequency of $i_{s}$ is constant when the wind speed changes; that is to say, the DFIG operates on variable-speed constant-frequency for our proposed passivity-based control strategy.

Figure 4(d) shows the $d$-q-axis components of the expected and actual stator currents $i_{s d}^{*}, i_{s d}, i_{s q}^{*}$, and $i_{s q}$, and Figure 4(e) shows the $d$-q-axis components of the expected and actual rotor currents $i_{r d}^{*}, i_{r d}, i_{r q}^{*}$, and $i_{r q}$. The expected values $i_{s d}^{*}, i_{s q}^{*}, i_{r d}^{*}$, and $i_{r q}^{*}$ are calculated by $(20)$. We can see that $i_{s d}^{*}$ keeps constant at zero in accordance with $Q_{s}^{*}=0$, and $i_{r d}^{*}$ remains unchanged because $\psi_{s}^{*}$ is constant. $i_{s q}^{*}, i_{r q}^{*}$ change after $t=5 \mathrm{~s}$ because $T_{e}^{*}$ changes after $t=5 \mathrm{~s}$. In addition, the actual currents $i_{s d}, i_{s q}, i_{r d}$, and $i_{r q}$ track the expected values $i_{s d}^{*}$, $i_{s q}^{*}, i_{r d}^{*}$, and $i_{r q}^{*}$ well for our proposed passivity-based control strategy.

From the above simulation results we have acquired the signals of the DFIG. We use WVD and CWT to analyze these signals to demonstrate the effectiveness of our proposed method from the perspective of energy distribution in time 


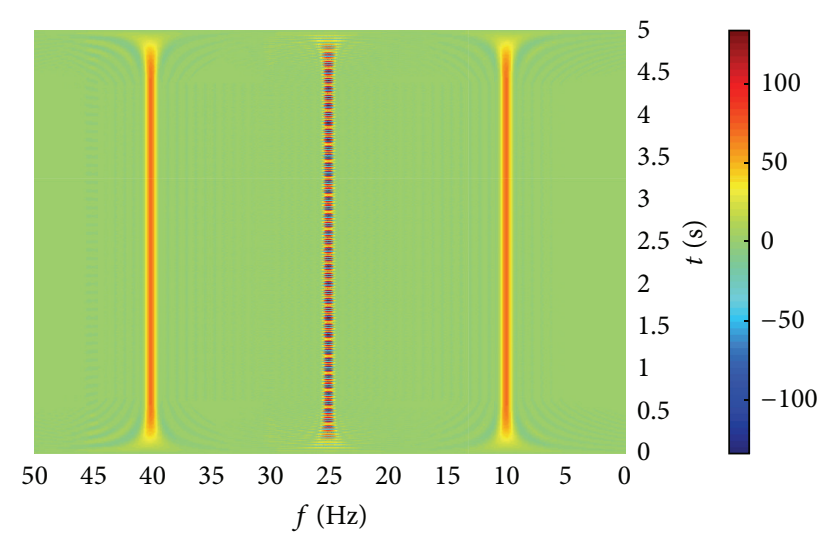

Figure 5: WVD of the test signal.

and frequency domain. The WVD of a signal $x(t)$ is given by [20]

$$
\begin{aligned}
& \operatorname{WVD}_{x}(t, \Omega) \\
& \quad=\int_{-\infty}^{+\infty} x\left(t+\frac{\tau}{2}\right) x^{*}\left(t-\frac{\tau}{2}\right) \exp (-j \Omega \tau) d \tau .
\end{aligned}
$$

We can also express the frequency-domain WVD of $x(t)$ as

$$
\begin{aligned}
& \operatorname{WVD}_{x}(t, \Omega) \\
& \quad=\frac{1}{2 \pi} \int_{-\infty}^{+\infty} X\left(\Omega+\frac{\theta}{2}\right) X^{*}\left(\Omega-\frac{\theta}{2}\right) \exp (j t \theta) d \theta,
\end{aligned}
$$

where $X(\Omega)$ is the Fourier transform of $x(t)$.

In order to test the signal's additivity property, we have written a WVD program in MATLAB. The test signal is $x(t)=$ $\sin (20 \pi t)+\sin (80 \pi t) 0 \leq t \leq 5$. Figure 5 shows the WVD result of the test signal, from which we can clearly see that a cross-term appears at $25 \mathrm{~Hz}$. The reason for this can be seen from (30). Only at $25 \mathrm{~Hz}, X^{*}(\Omega-\theta / 2)$ and $X(\Omega+\theta / 2)$ can have nonzero overlapping contributions.

The analyzing function of continuous wavelet transforms (CWT) is a wavelet $\psi(t)$. The CWT compares the signal to shifted and compressed or stretched versions of a wavelet. Stretching or compressing a function is collectively referred to as dilation or scaling and corresponds to the physical notion of scale. By comparing the signal to the wavelet at various scales and positions, we obtain a function of two variables [21]. For a scale parameter $a>0$, and a position parameter $b$, the CWT is

$$
C(a, b ; f(t), \psi(t))=\int_{-\infty}^{+\infty} f(t) \frac{1}{\sqrt{a}} \psi^{*}\left(\frac{t-b}{a}\right) d t,
$$

where $*$ denotes the complex conjugate. By continuously varying the values of the scale parameter $a$ and the position parameter $b$, we obtain the CWT coefficients $C(a, b)$. Note that the values of scale and position affect not only the CWT coefficients, but also the choice of the wavelet.

More details on the WVD and CWT methods can be found in [22-24]. Unlike the WVD, the CWT timefrequency representation does not exhibit a cross-term.
Both WVD and CWT time-frequency representations provide a mapping from time domain to time-frequency plane, which means that both allow analyzing signals in both time and frequency domain. The corresponding WVD results for the rotor current signal and the stator current signal are shown in Figure 6, and the associated CWT results are presented in Figure 7.

Regarding the results of the WVD, from Figure 6(a), we can see that the primary frequency of the rotor current changes from $65 \mathrm{~Hz}$ to $53 \mathrm{~Hz}$ approximately after $t=5 \mathrm{~s}$. In addition, the energy values of rotor current wave keep constant whose maximum value is 25000 , indicating that the rotor current's amplitude does not vary when the wind speed gets stronger. Therefore, the WVD result is in accordance with Figure 4(b).

The primary frequency of the stator current signal in Figure 6(b) keeps constant when wind speed changes, and the maximum energy value reaches 450 before $t=5 \mathrm{~s}$, while after $t=5 \mathrm{~s}$ it increases to 1600 . These results show that the stator current's amplitude has increased dramatically when the wind speed gets stronger. It is in line with Figure 4(c).

Turning to the results based on CWT, Figure 7(a) reveals that after $t=5 \mathrm{~s}$ the primary frequency of the rotor current decreases when the wind speed increases at $t=5 \mathrm{~s}$. In the meantime, we can see that, before and after $t=5 \mathrm{~s}$, the energy value of the rotor current wave keeps constant with a maximum of 72 . This indicates that the rotor current's amplitude does not vary when the wind speed gets stronger. The conclusion is in accordance with Figure 4(b).

The CWT result of stator current signal in Figure 7(b) again shows that the primary frequency keeps constant when the wind speed increases, which demonstrates that the constant frequency of the DFIG connected to the grid is realized by our proposed method. Meanwhile, the maximum energy value reaches 8 before $5 \mathrm{~s}$, and it increases to 10 after $5 \mathrm{~s}$, indicating that the stator current's amplitude has increased.

\section{Conclusions}

In order to improve the performance of the DFIG system, in this paper, we have investigated and proposed a nonlinear PBC strategy on the DFIG. We have built a PBC model of the DFIG in a two-phase rotating reference frame and designed the passive controller for the inner loop. Then we have calculated the rotor control voltages. Furthermore, our simulations and time-frequency representation results have verified that the rotor speed and DFIG currents fast track their expected values and that the independent regulation of stator active power and reactive power is achieved. In summary, we have drawn the following conclusions:

(1) The proposed method is simple and has strong robustness.

(2) The static and dynamic performances of the whole system have been improved.

(3) The independent regulation of the stator active power and reactive power has been achieved. 


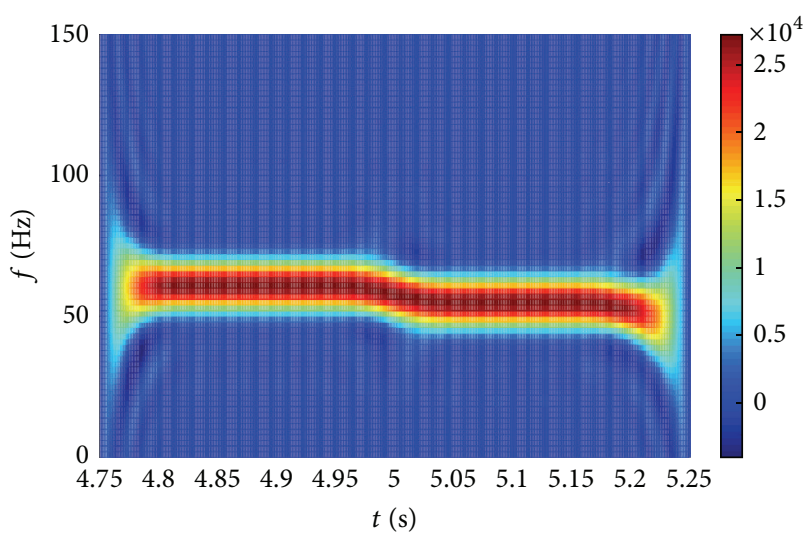

(a)

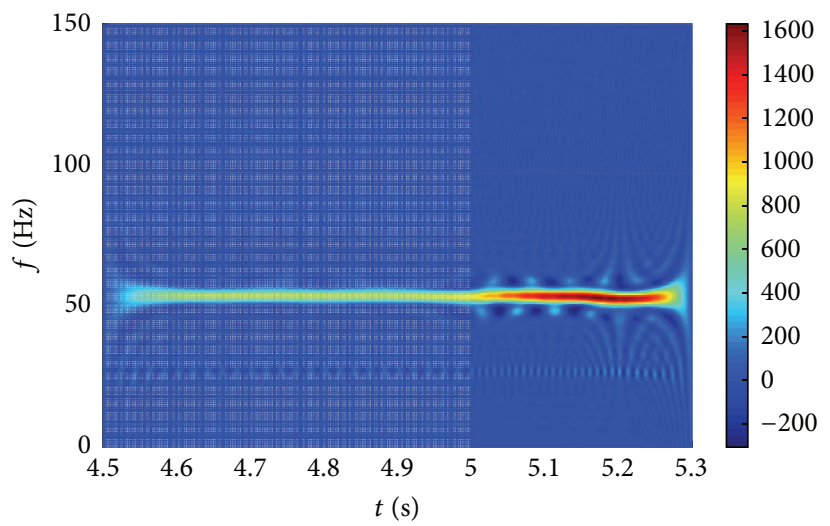

(b)

FIGURE 6: WVD results: (a) WVD of the rotor current signal and (b) WVD of the stator current signal.

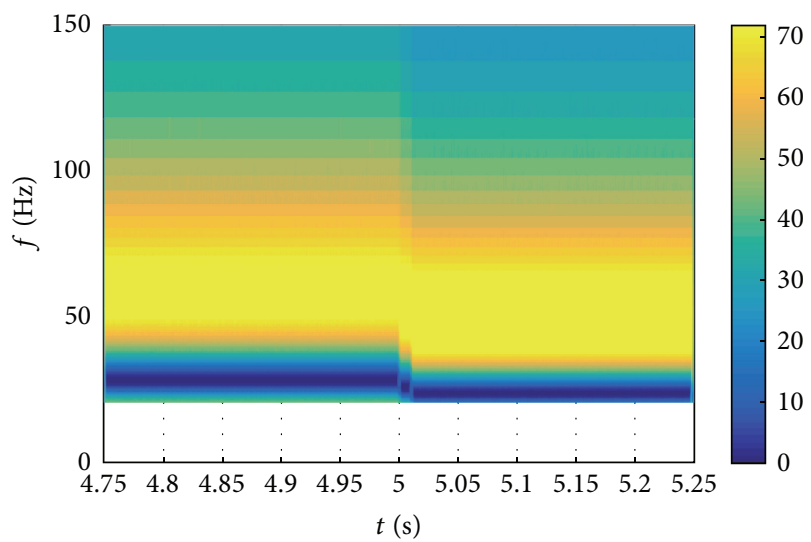

(a)

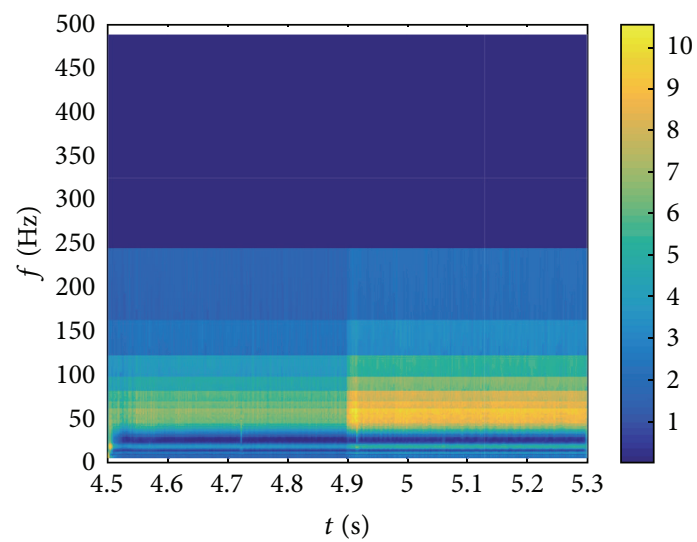

(b)

FIGURE 7: CWT results: (a) CWT of the rotor current signal and (b) CWT of the stator current signal.

(4) Both time-frequency representation methods (WVD and CWT) can be successfully used to analyze the DFIG system's signals.

In this paper, we have chosen time-frequency representation to analyze our signals aiming to observe the energy distribution in time-frequency plane. We also note the recent development on nonlinear time series analysis. Methods such as recurrence plots [25] and complex network analysis [26] have been demonstrated to be powerful tools for probing time series. These methods have been successfully applied to solve real challenging problems. In further work, we plan to employ these methods to further characterize our signals and investigate the underlying nonlinear behavior.

\section{Conflict of Interests}

The authors declare that there is no conflict of interests regarding the publication of this paper.

\section{Acknowledgments}

This work has been supported by "the Fundamental Research Funds for the Central Universities (2014MS89) and (13MS72)" and "the Natural Science Foundation of Hebei Province (E2015502012)".

\section{References}

[1] J. B. Hu, Y. He, L. Xu, and B. W. Williams, "Improved control of DFIG systems during network unbalance using PI-R current regulators," IEEE Transactions on Industrial Electronics, vol. 56, no. 2, pp. 439-451, 2009.

[2] J. B. Hu, Y. K. He, and L. Xu, "Improved rotor current control of wind turbine driven doubly-fed induction generators during network voltage unbalance," Electric Power Systems Research, vol. 80, no. 7, pp. 847-856, 2010.

[3] W. Chen, C. Chen, and Z. F. Song, "Proportional-resonant control for dual PWM converter in doubly fed wind generation 
system," Proceedings of the Chinese Society of Electrical Engineering, vol. 29, no. 15, pp. 1-7, 2009.

[4] L. Fan, R. Kavasseri, Z. L. Miao, and C. Zhu, "Modeling of DFIG-based wind farms for SSR analysis," IEEE Transactions on Power Delivery, vol. 25, no. 4, pp. 2073-2082, 2010.

[5] A. Ostadi, A. Yazdani, and R. K. Varma, "Modeling and stability analysis of a DFIG-based wind-power generator interfaced with a series-compensated line," IEEE Transactions on Power Delivery, vol. 24, no. 3, pp. 1504-1514, 2009.

[6] X. L. Ji, C. W. Shen, and Y. Q. Meng, "Research on the stable condition of the passivity based control system for induction motor," Transactions of China Electrotechnical Society, vol. 22, pp. 46-54, 2007.

[7] T. Wang, J. Xiao, and J.-K. Li, "Passivity analysis of induction motor and adaptive control," Proceedings of the Chinese Society of Electrical Engineering, vol. 27, no. 6, pp. 31-34, 2007.

[8] P. Yang, W. Chen, and S. H. Liu, "Speed control of induction motor based on passivity theory," Proceedings of the CSU-EPSA, vol. 19, pp. 73-77, 2007.

[9] T. Wang, J. Xiao, and J. K. Li, "Passivity analysis of induction motor and adaptive control," Proceedings of the CSEE, vol. 27, pp. 31-34, 2007.

[10] Y. Gao, W. Zhang, Y. Yang, and T. An, "Passivity-based control system for VSCF doubly fed wind power generator," Transactions of China Electrotechnical Society, vol. 25, no. 7, pp. 130-136, 2010.

[11] L. Xu, "Enhanced control and operation of DFIG-based wind farms during network unbalance," IEEE Transactions on Energy Conversion, vol. 23, no. 4, pp. 1073-1081, 2008.

[12] Z. J. Wu, C. X. Zhu, and M. Q. Hu, "Supplementary controller design for SSR damping in a series-compensated DFIG-based wind farm," Energies, vol. 5, no. 11, pp. 4481-4496, 2012.

[13] Z. F. Song, C. L. Xia, and T. N. Shi, "Assessing transient response of DFIG based wind turbines during voltage dips regarding main flux saturation and rotor deep-bar effect," Applied Energy, vol. 87, no. 10, pp. 3283-3293, 2010.

[14] S. G. Jiang, W. Wang, P. B. Wang, and G. H. Liu, "Power-feed forward-based control strategy of grid-connected single-phase PV system," Electric Power Automation Equipment, vol. 30, pp. 25-30, 2010.

[15] Y. F. Tian, X. C. Li, J. H. Xu, L. Gu, and M. Huang, "Nonlinear control strategy of variable-speed constant-frequency wind turbine driven doubly-fed induction generator for maximum wind energy capture," Automation of Electric Power Systems, vol. 35, no. 11, pp. 27-32, 2011.

[16] C. N. Papadimitriou and N. A. Vovos, "Transient response improvement of microgrids exploiting the inertia of a DoublyFed induction Generator (DFIG)," Energies, vol. 3, no. 6, pp. 1049-1066, 2010.

[17] T. Y. Zhou, Study on the technology of converter for doublyfed induction wind generator [M.S. thesis], Southwest Jiaotong University, Chengdu, China, 2009.

[18] R. Fadaeinedjad, M. Moallem, and G. Moschopoulos, "Simulation of a wind turbine with doubly fed induction generator by FAST and Simulink," IEEE Transactions on Energy Conversion, vol. 23, no. 2, pp. 690-700, 2008.

[19] T. K. A. Brekken and N. Mohan, "Control of a doubly fed induction wind generator under unbalanced grid voltage conditions," IEEE Transactions on Energy Conversion, vol. 22, no. 1, pp. 129135, 2007.
[20] Y. Zhou, J. Chen, G. M. Dong, W. B. Xiao, and Z. Y. Wang, "Wigner-Ville distribution based on cyclic spectral density and the application in rolling element bearings diagnosis," Proceedings of the Institution of Mechanical Engineers, Part C: Journal of Mechanical Engineering Science, vol. 225, no. 12, pp. 2831-2847, 2011.

[21] Y.-F. Sang, "A review on the applications of wavelet transform in hydrology time series analysis," Atmospheric Research, vol. 122, pp. 8-15, 2013.

[22] P. Chaovalit, A. Gangopadhyay, G. Karabatis, and Z. Y. Chen, "Discrete wavelet transform-based time series analysis and mining," ACM Computing Surveys, vol. 43, pp. 37-43, 2011.

[23] Y. Wang and Y.-C. Jiang, "Realization of the polynomial Wigner-Ville distribution (PWVD) based on the convolution in frequency domain," Dianzi Yu Xinxi Xuebao, vol. 30, no. 2, pp. 286-289, 2008.

[24] C. Torrence and G. P. Compo, "A practical guide to wavelet analysis," Bulletin of the American Meteorological Society, vol. 79, no. 1, pp. 61-78, 1998.

[25] N. Marwan, J. Kurths, and S. Foerster, "Analysing spatially extended high-dimensional dynamics by recurrence plots," Physics Letters A, vol. 379, no. 10-11, pp. 894-900, 2015.

[26] N. Marwan, J. F. Donges, Y. Zou, R. V. Donner, and J. Kurths, "Complex network approach for recurrence analysis of time series," Physics Letters A, vol. 373, no. 46, pp. 4246-4254, 2009. 


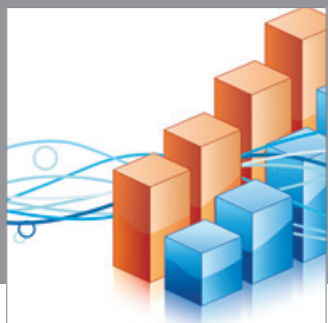

Advances in

Operations Research

mansans

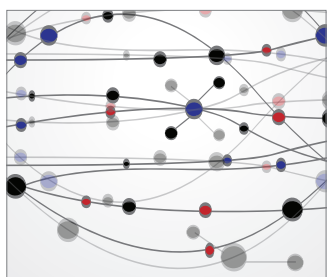

The Scientific World Journal
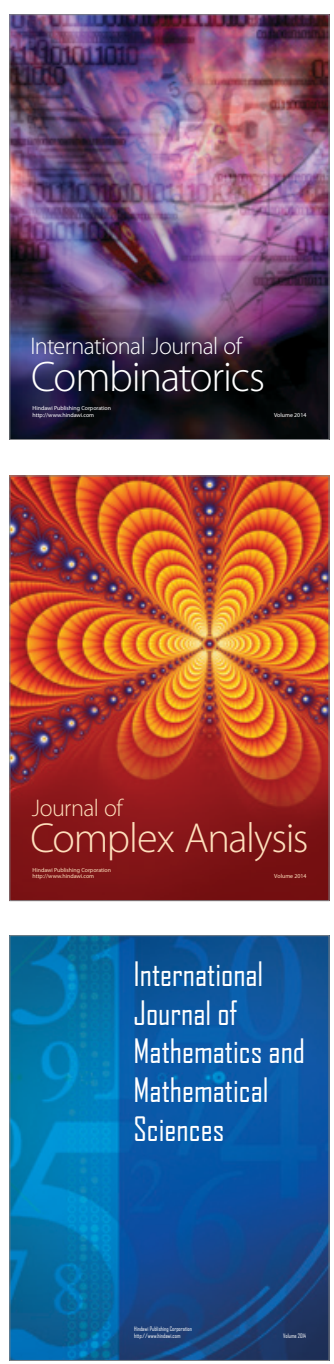
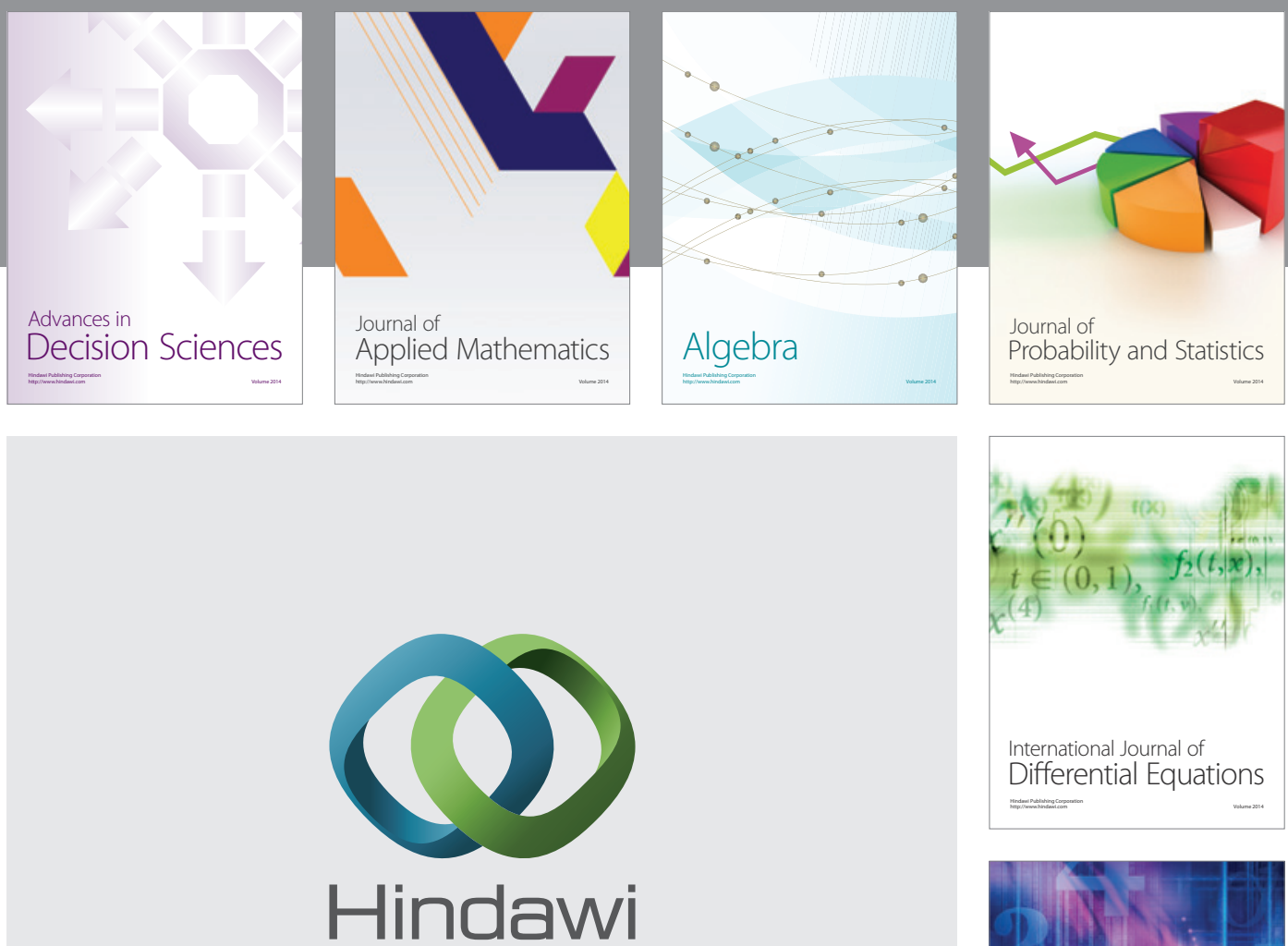

Submit your manuscripts at http://www.hindawi.com
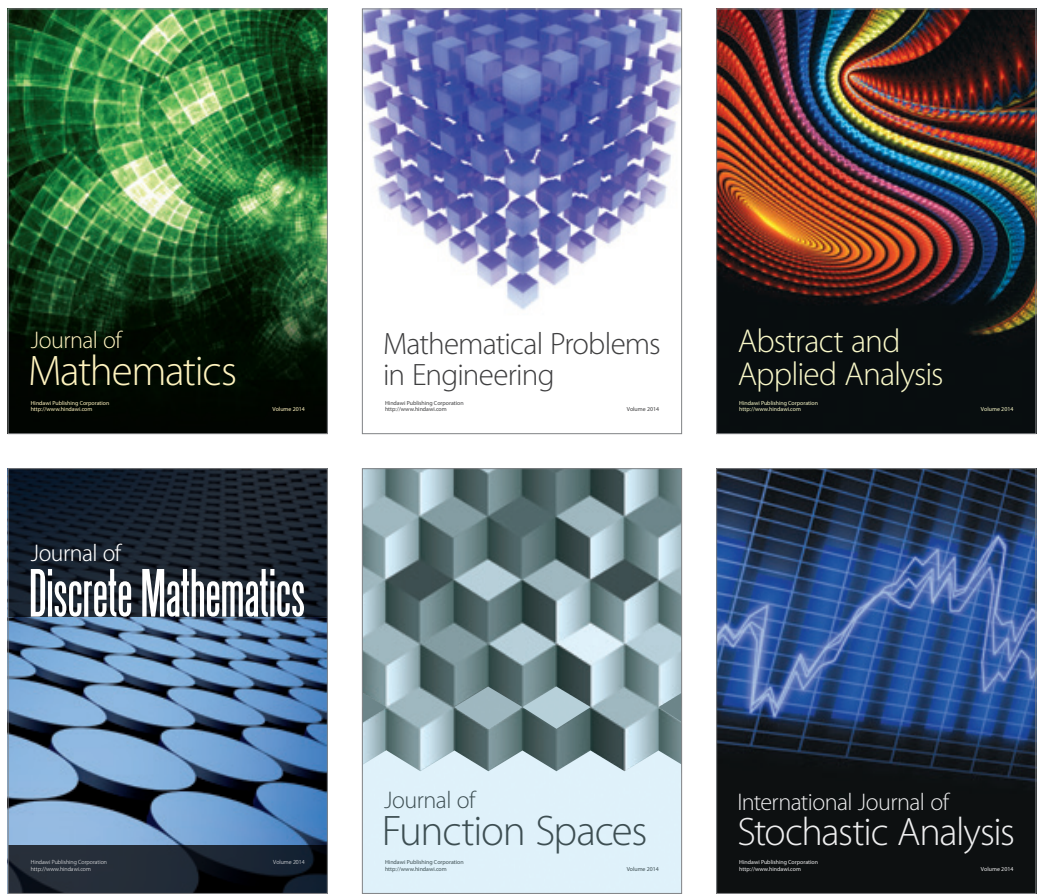

Journal of

Function Spaces

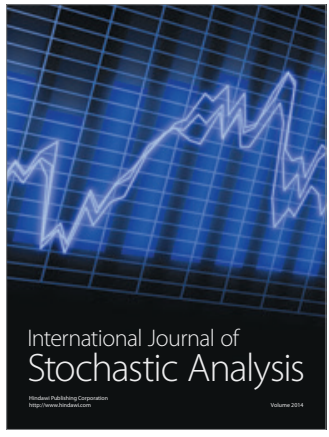

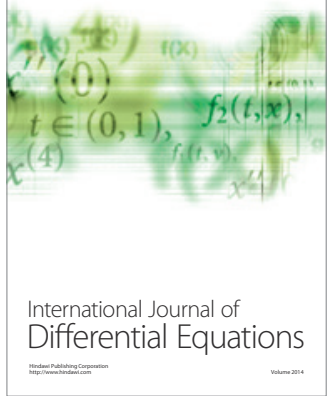
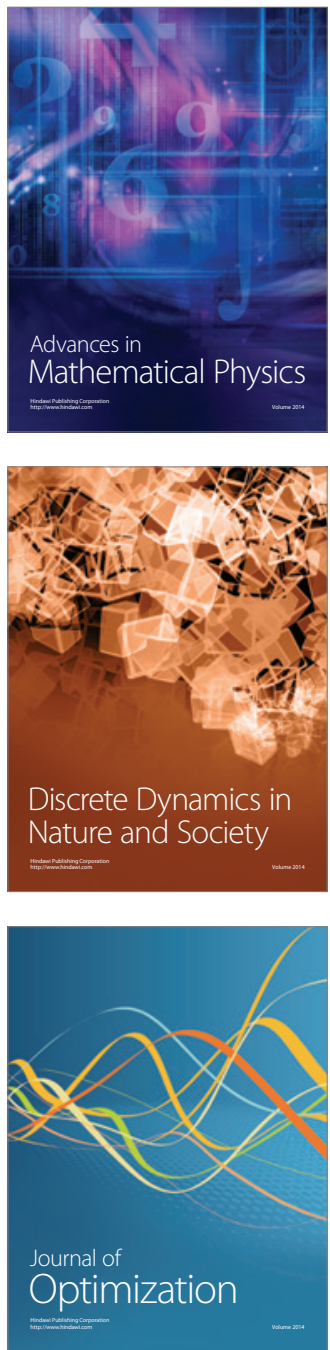